\title{
CAPÍTULO 08: PERSPECTIVA DO PROTAGONISMO ESTUDANTIL POR ESTUDANTES DO CURSO DE SANEAMENTO DO IFPE - CAMPUS RECIFE
}

\author{
CAPÍTULO 08: PERSPECTIVA DEL PROTAGONISMO ESTUDIANTIL POR \\ ESTUDIANTES DEL CURSO DE SANEAMIENTO DEL IFPE - CAMPUS RECIFE
}

\section{CHAPTER 08: PERSPECTIVE OF STUDENT PROTAGONISM BY STUDENTS FROM THE SANITATION COURSE OF IFPE - RECIFE CAMPUS}

\author{
Fábio de Lima Ferreira Papais ${ }^{1}$; Marnix Carlos de Vocht ${ }^{2}$
}

DOI: $\underline{\text { https://doi.org/10.31692/978-65-88970-03-4.120-139 }}$

\begin{abstract}
RESUMO
Os Projetos Pedagógicos dos cursos de Saneamento do IFPE - campus Recife destacam entre seus objetivos específicos a formação de profissionais não apenas com conhecimentos técnicos e teóricos, mas com competências comportamentais, interpessoais e éticas. O protagonismo estudantil vem como alternativa aos modelos tradicionais de educação e desenvolvimento, quebrando as barreiras comuns entre os estudantes e os adultos, tornando-os agentes de seu próprio aprendizado. As atividades extracurriculares tendem a incentivar maior participação e engajamento discente, essenciais para a promoção do protagonismo estudantil; dessa forma, as principais atividades extracurriculares do campus foram mapeadas e utilizadas para o desenvolvimento de uma pesquisa aplicada, com abordagem quali-quantitativa, a partir da aplicação de um questionário enviado pela internet. Foram obtidas 37 respostas de estudantes de Saneamento e, a fim de auxílio e comparação, 439 respostas de discentes de todos cursos técnicos e superiores do campus. $\mathrm{O}$ questionário se concentrou em três principais aspectos relativos as atividades extracurriculares mapeadas: participação, acreditação (ou interesse) e estímulo. Com relação à participação, observou-se grande incongruência entre a maioria dos estudantes apresentarem alta aptidão a desenvolver novos projetos e os baixos índices de participação nas atividades extracurriculares, principalmente as atividades de pesquisa e extensão, que, junto com o ensino, constituem um dos principais eixos pedagógicos do IFPE. Quanto à acreditação ou interesse, em contraste com as atividades extracurriculares, a maioria dos estudantes consideraram os modelos tradicionais de ensino como os mais impactantes para o seu desenvolvimento acadêmico e pessoal. As respostas dos estudantes sobre o estímulo recebido para a participação nestas atividades extracurriculares mostraram que eles consideram o IFPE como Instituição estimuladora do protagonismo estudantil; mesmo assim, puderam indicar que carecem de maior incentivo dos professores ou até mesmo de baixa iniciativa pessoal entre os estudantes de Saneamento.

Palavras-Chave: Protagonismo estudantil, Curso de Saneamento, IFPE.
\end{abstract}

\section{RESUMEN}

Los proyectos Pedagógicos de los cursos de Saneamiento en IFPE - campus Recife destacan entre sus objetivos específicos la formación de profesionales no solo con conocimientos técnicos y teóricos, sino con habilidades conductuales, interpersonales y éticas. El protagonismo estudiantil surge como una alternativa a los modelos tradicionales de educación y desarrollo, rompiendo las barreras comunes entre estudiantes y adultos, transformándolos en agentes de su propio aprendizaje. Las actividades extracurriculares tienden a fomentar una mayor participación y compromiso de los estudiantes, que son esenciales para promover el protagonismo estudiantil; así, se mapearon las principales actividades extraescolares del campus y se utilizaron para el desarrollo de la investigación aplicada, con un enfoque cualitativo y cuantitativo, a partir de la aplicación de un cuestionario enviado a través de Internet. Se obtuvieron 37 respuestas de estudiantes de Saneamiento y, para ayuda y comparación, 439

1 Aluno do Curso Técnico Integrado em Eletrônica, Instituto Federal de Pernambuco flfp@discente.ifpe.edu.br

2 Mestre em Administração pela Fundação Getúlio Vargas (FGV/SP), Professor do Instituto Federal de Pernambuco - campus Recife, marnixcarlos@recife.ifpe.edu.br 
respuestas de estudiantes de todos los cursos técnicos y universitarios del campus. El cuestionario se centró en tres aspectos principales relacionados con las actividades extracurriculares mapeadas: participación, acreditación y estímulo. En cuanto a la participación, se observó una gran inconsistencia entre la mayoría de estudiantes con alta aptitud para el desarrollo de nuevos proyectos y bajas tasas de participación en actividades extraescolares, especialmente en las actividades de investigación y extensión, que junto a la docencia constituyen una de los principales ejes pedagógicos de IFPE. En cuanto a la acreditación o el interés, a diferencia de las actividades extracurriculares, la mayoría de los estudiantes considera que los modelos de enseñanza tradicionales son los más impactantes para su desarrollo académico y personal. Las respuestas de los estudiantes al estímulo recibido por la participación en estas actividades extracurriculares mostraron que consideran al IFPE como una institución que estimula el protagonismo estudiantil; aun así, pudieron indicar que carecen de mayor estímulo por parte de los docentes o incluso de poca iniciativa personal entre los estudiantes de Saneamiento.

Palabras Clave: Protagonismo Estudiantil, Cursos de Saneamiento, IFPE.

\begin{abstract}
The Pedagogical Projects of the Sanitation courses at IFPE - campus Recife highlight among their specific objectives the training of professionals not only with technical and theoretical knowledge, but also with behavioral, interpersonal and ethical skills. Student protagonism comes as an alternative to traditional models of education and academic development, breaking the common barriers between students and adults, making them agents of their own learning. Extracurricular activities tend to encourage greater participation and student engagement, which are essential for promoting student protagonism; thus, the main extracurricular activities on campus were mapped and used for the development of an applied research, with a qualitative and quantitative approach, based on the application of a questionnaire sent over the internet. 37 responses were obtained from Sanitation students and, for measurement and comparison, 439 responses from students from all technical and university courses on campus. The questionnaire focused on three main aspects related to the mapped extracurricular activities: participation, accreditation (or interest) and incentive. Regard to the participation, inconsistencies were observed between most students showing high aptitude for developing new projects but low participation rates observed in extracurricular activities, especially research and extension activities, which, together with teaching, constitute one of the main pedagogical axes of IFPE. When analyzing the accreditation or interest, in contrast to extracurricular activities, most students considered traditional teaching models to be the most impactful for their academic and personal development. The students responses to the stimulus received for participation in these extracurricular activities showed that they consider IFPE as an institution that stimulates student protagonism; even so, they were able to indicate that they lack of greater incentive from their teachers or even low personal initiative among Sanitation students.
\end{abstract}

Keywords: Student Protagonism, Sanitation course, IFPE.

\title{
INTRODUÇÃO
}

A Psicologia sugere a "crise da adolescência": momento de incertezas, emoções e inseguranças, no qual o jovem ainda não é plenamente considerado um adulto e ainda não usufrui da mesma independência e dos mesmos deveres de um. Esta é uma fase de muita tensão e conflitos, podendo gerar problemas como ansiedade, estresse, depressão e exclusão social. Segundo Aberastury e Knobel (1981, p. 30), “A criança entra na adolescência com dificuldades, conflitos e incertezas que se magnificam neste momento vital, para sair em 
seguida à maturidade estabilizada com determinado caráter e personalidade adultos". Nesse cenário surge o protagonismo estudantil, como uma forma de incluir os adolescentes em espaços e situações onde não participam com frequência ou facilidade, perpassando as comuns barreiras entre os adultos que já trabalham e adolescentes que estão em fase escolar, além de criar um ambiente mais democrático e receptivo à participação dos estudantes.

Os Projetos Pedagógicos do Curso de Saneamento tanto da modalidade Integrado (IFPE, 2013a) quanto Subsequente (IFPE, 2013b) do IFPE destacam entre seus objetivos específicos a formação de profissionais não somente com conhecimentos técnicos e teóricos, mas com competências relativas à liderança, iniciativa, multifuncionalidade, trabalho em equipe, espírito empreendedor, responsabilidade social e ambiental. Segundo Costa (2000), o protagonismo estimula o desenvolvimento da auto-gestão (reconhecer suas potencialidades e limitações), heterogestão (coordenação do trabalho de outros) e o trabalho em equipe. Nesta proposta, torna-se ainda mais importante a abordagem de metodologias que envolvam o protagonismo estudantil. O IFPE - campus Recife faz parte deste esforço ao incluir na maioria dos cursos ofertados disciplinas que abordam tanto empreendedorismo como conceitos de administração, indo de encontro com características, segundo Filion (2000), comumente apresentadas por empreendedores: liderança, diferenciação, visão, bom uso de recursos, etc.

Porém, em 108 anos de existência, esta Instituição ainda não possui uma empresa júnior, incubadora ou aceleradora de negócios. De fato, o Instituto ocupa pouco espaço no conjunto de escolas que são protagonistas em exportar empresas, empresas júniores e startups. A presente pesquisa visa analisar de forma detalhada esta questão à luz do protagonismo estudantil por estudantes do curso de Saneamento do IFPE - campus Recife. Esta pesquisa desenvolveu-se nos seguintes objetivos específicos:

- Mapear eventos, cursos, competições e atividades que estão sendo promovidas no IFPE - campus Recife que estimulem o protagonismo estudantil.

- Identificar a participação dos estudantes nas principais atividades mapeadas.

- Analisar qual a importância das ações que estimulam o protagonismo estudantil para os estudantes do curso de Saneamento e quais as experiências e atividades consideradas mais importantes para o sucesso profissional e/ou acadêmico destes estudantes. 
- Analisar a percepção dos alunos de Saneamento sobre o incentivo de metodologias e atividades que estimulem o protagonismo estudantil pelos seus professores e pelo IFPE como Instituição.

\section{FUNDAMENTAÇÃO TEÓRICA}

Como ressaltam Ferretti, Zibas e Tartuce (2004), não há certo consenso na definição de protagonismo estudantil:

[..] a revisão bibliográfica sobre o tema indica que o "protagonismo dos jovens/alunos" é um conceito passível de diferentes interpretações e, além disso, imbrica outros conceitos igualmente híbridos, como "participação", "responsabilidade social", "identidade", "autonomia" e "cidadania". Nem mesmo a distinção conceitual entre "participação" e "protagonismo" é clara na bibliografia consultada (2004, p. 413).

Porém, após revisão de literatura, a presente pesquisa adota o protagonismo estudantil quando um estudante, a partir dos conhecimentos adquiridos em sala de aula e de sua participação criativa, construtiva e solidária, parte para a resolução de problemas reais e cotidianos (COSTA, 2000), tornando-se, enfim, um agente de seu próprio aprendizado.

O protagonismo envolve empoderar os alunos e os mais jovens das suas decisões na sociedade, estimulando-os a perceber que estas atitudes geram consequências, podem ser usadas para o bem geral e que eles também possuem a capacidade de modificar o ambiente em que vivem. Com comprometimento tanto docente como discente, esta ferramenta de aprendizado prepara o jovem para não só os conhecimentos técnicos que se desejam ensinar, mas como explicita Silva (2009, p. 43): “[...] oportuniza espaços e atividades de desenvolvimento humano a partir da crença que o(a) adolescente é capaz, trabalhando na dimensão de sua autopercepção, autoconfiança e sua auto-estima [sic]"; dessa forma, metodologias que incluem os conceitos do protagonismo estudantil podem também despertar autonomia, liberdade, cidadania e independência no aluno, qualidades que farão grande diferença em seu desenvolvimento pessoal, acadêmico e/ou profissional. Sobre os benefícios que a autonomia e independência do estudante podem proporcionar, Much et al. $(2018$, p. 8) conclui, após pesquisa com docentes e discentes de uma escola de Educação Básica, acerca de métodos pedagógicos protagonistas: “[..] ficou claro que os alunos foram além das pesquisas inicialmente previstas, fazendo novas investigações e analisando até mesmo aspectos de outras nações, permitindo assim aumentar o interesse, as curiosidades e a criatividade dos mesmos". 
Evidentemente, o objetivo é que o personagem principal da resolução dos problemas seja o estudante, pois a produção de conhecimento e o desenvolvimento do educando se dá a partir da atuação do próprio aluno (STOCKMANNS, 2014). Mesmo assim, vale ressaltar a importância de um orientador na abordagem de uma metodologia protagonista, já que, segundo Costa (2000), os jovens (ou adolescentes) não são detentores de total autonomia, como os adultos, e nem totalmente heterônomos, como as crianças.

\section{METODOLOGIA}

Inicialmente, uma revisão bibliográfica foi feita para a maior familiarização com o tema do protagonismo estudantil e seus conceitos. Porém, concentrou-se no desenvolvimento de uma pesquisa aplicada, que, segundo Fleury e Werlang (2017), focam-se em torno dos problemas presentes nas atividades das instituições, organizações, grupos e atores sociais. Foi adotada uma abordagem quali-quantitativa, elaborando-se um questionário, que segundo Lakatos e Marconi (2003), são aplicados quando o pesquisador não está presente. As questões ordenadas abertas (discursivas) e fechadas (opções de múltipla escolha) foram elaboradas de acordo com os principais conceitos do protagonismo estudantil.

O questionário foi enviado aos alunos por meio da internet durante o período de 19/05/2020 a 11/07/2020. A aplicação se deu através da plataforma Google Forms, meio avaliado apropriado e eficiente para o contexto atual de pandemia do COVID-19. Como o Diagrama 1 representa, é formado de 33 a 35 perguntas separadas em 4 a 5 seções diferentes. A variação na quantidade de perguntas e seções se deve ao fato de a resposta na seção 3 poder adicionar 2 perguntas relacionadas. 
Diagrama 1 - Representação do questionário aplicado aos discentes do curso de Saneamento do IFPE - campus Recife

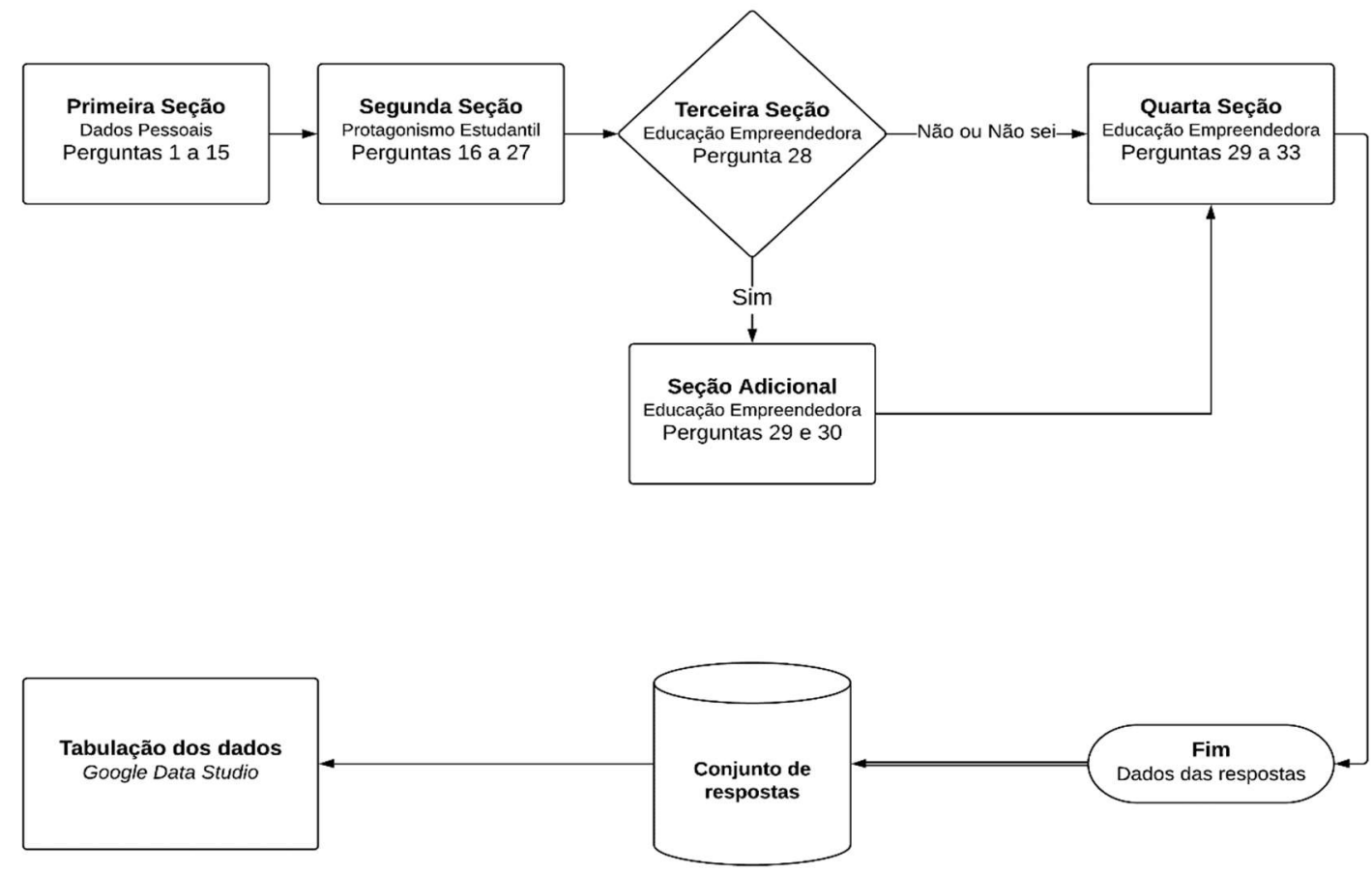

Fonte: Própria (2020)

As respostas foram armazenadas em uma planilha por plataforma online e como o Diagrama 1 também ressalta, o tratamento e tabulação dos dados foram feitos a partir da ferramenta Google Data Studio, que permitiu maior facilidade e agilidade na elaboração de diferentes relações e conclusões acerca dos dados.

\section{RESULTADOS E DISCUSSÃO}

O IFPE - campus Recife passou a ofertar o curso de Saneamento a partir do ano 2013 e segundo dados informados pela gestão (IFPE, 2020), possui atualmente 267 alunos matriculados na modalidade Integrado e 221 alunos matriculados na modalidade Subsequente, apresentando um total de 488 alunos matriculados no curso de Saneamento. Quanto a esta métrica, o curso de Saneamento se mantém equilibrado quando comparado a outros cursos com dupla modalidade (Integrado e Subsequente), tanto na diferença entre os números em cada modalidade quanto em números totais. O contexto atual de pandemia do novo coronavírus (COVID-19), isolamento social e quarentena, acarretaram na suspensão das aulas presenciais no IFPE - campus Recife por tempo indeterminado, dificultando a aquisição de respondentes ao questionário descrito no tópico anterior. Mesmo assim, foram obtidas 37 respostas de discentes dos cursos Integrado e Subsequente de Saneamento. Também foram 
obtidas, a fim de comparação e auxílio, 439 respostas de discentes de todos os cursos presenciais técnicos e superiores do IFPE - campus Recife. Vale ressaltar que todas descrições se referem à amostragem principal (curso de Saneamento), salvo quando citada a amostragem auxiliar (cursos técnicos e superiores do IFPE - campus Recife). A análise da amostragem principal se manteve, na maioria dos casos, semelhante à amostragem auxiliar, porém, em alguns casos, diferenças foram notadas, as quais serão elucidadas adiante.

\section{Perfil da amostragem}

\subsection{Perfil socioeconômico}

Como descrito anteriormente, foram elaboradas perguntas de forma a traçar um perfil socioeconômico dos respondentes. Mesmo que à luz do protagonismo estudantil observem-se regularidades de comportamento e desenvolvimento entre jovens, Ferreti, Zibas e Tartuce (2004) destacam que é preciso prestar atenção às variações de condições de vida, trabalho, educação, poder aquisitivo, etc., presentes na vida também dos jovens; dessa forma, faz-se importante analisar as diversidades dentro da adolescência, sem a encarar como sendo homogênea ou única. A faixa etária da amostragem principal se concentrou principalmente entre os jovens de 13-20 anos: discentes de 13-16 anos representam 37,8\% do total e discentes na faixa dos $17-20$ anos compõem $37,8 \%$ do total; os $24 \%$ restantes se distribuem na faixa acima dos 21 anos, destacando a presença de 2 discentes com idade acima dos 27 anos. O gênero predominante na amostragem principal é o Feminino (64,9\%), e, como o Gráfico 1 demonstra, há diferença em comparação com a amostragem auxiliar, cujo grupo Feminino representa $51 \%$ das respostas.

Gráfico 1 (a): Distribuição por sexo na amostragem principal

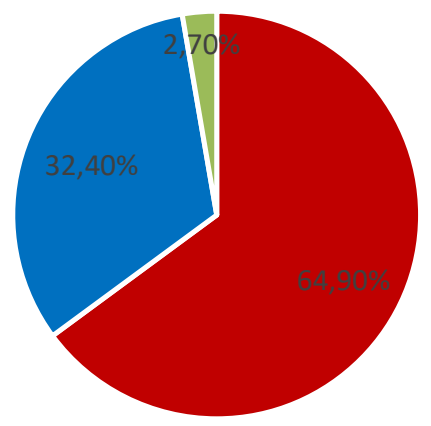

- Feminino

- Masculino

- Prefiro não dizer
Gráfico 2 (b): Distribuição por sexo na amostragem auxiliar

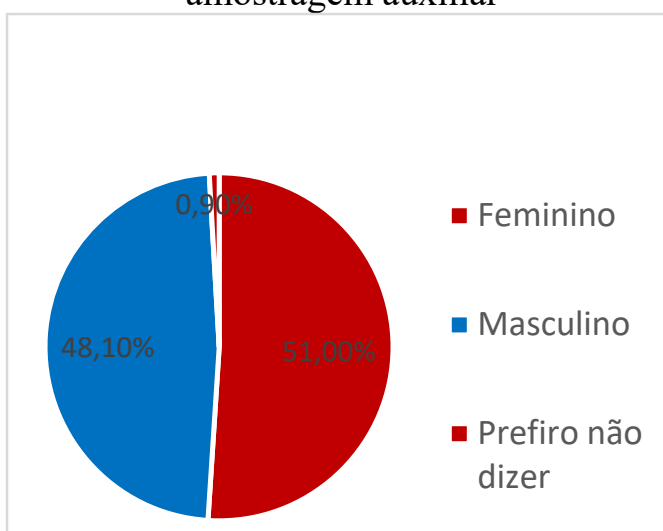


Com relação à renda familiar total, a faixa de até 3 salários mínimos predomina, representando $81 \%$ das respostas: $40,5 \%$ até 1 salário mínimo e 40,5\% na faixa de 1-3 salários mínimos. Os dados sobre a realização de atividades não acadêmicas renumeradas se divide entre $78,4 \%$ e $21,6 \%$ de estudantes que não exercem e exercem este tipo de atividades, respectivamente. Ligado aos objetivos do plano de pesquisa geral, 43,2\% dos discentes alegam que seus pais possuem atividade empresarial formal ou informal. Também foram analisados os conhecimentos em idiomas estrangeiros: 46,9\% dos alunos conseguem se comunicar em inglês, seguido do espanhol, estando em 29,7\% das respostas; $37,8 \%$ dos estudantes não se comunicam em nenhum outro idioma estrangeiro. Por fim, quanto a etnia, $45,9 \%$ dos estudantes se identificaram como pardo, 35,1\% como branco, $13,5 \%$ como afrodescendente, $2,7 \%$ como indígena e $2,7 \%$ como amarelo.

\subsection{Perfil escolar dentro do IFPE}

A partir dos dados coletados na primeira seção do questionário, também foram obtidos dados acerca do perfil do discente dentro do IFPE. A amostragem principal é composta principalmente por estudantes da modalidade Integrado: $70,3 \%$ se concentram nesta modalidade, enquanto os $29,7 \%$ restantes representam os respondentes da modalidade Subsequente. Os turnos se dividiram em $48,6 \%$ para tarde, $43,2 \%$ para manhã e $8,1 \%$ no turno da noite. É interessante notar, como representado no Gráfico 2, a grande alteração na distribuição dos alunos ao cruzar os dados da modalidade e do turno entre a amostragem principal e auxiliar: Ao analisarmos a modalidade Integrado da amostragem principal (Gráfico 2a), percebe-se maior concentração de estudantes no turno da tarde do que na manhã (61,5\% e 38,5\%, respectivamente), proporção que não se repete ao olharmos para a amostragem auxiliar (Gráfico $2 b$ ), onde a concentração de estudantes é maior no turno da manhã. Analisando a modalidade Subsequente, observa-se o sentido contrário: enquanto na amostragem principal a concentração no turno da manhã é maior $(54,5 \%)$, na amostragem auxiliar o mesmo turno representa apenas $12,5 \%$ da concentração, com os turnos da tarde e da noite apresentando maiores porcentagens. 
Gráfico 2 (a): Distribuição de alunos por modalidade nos dois turnos da amostragem principal

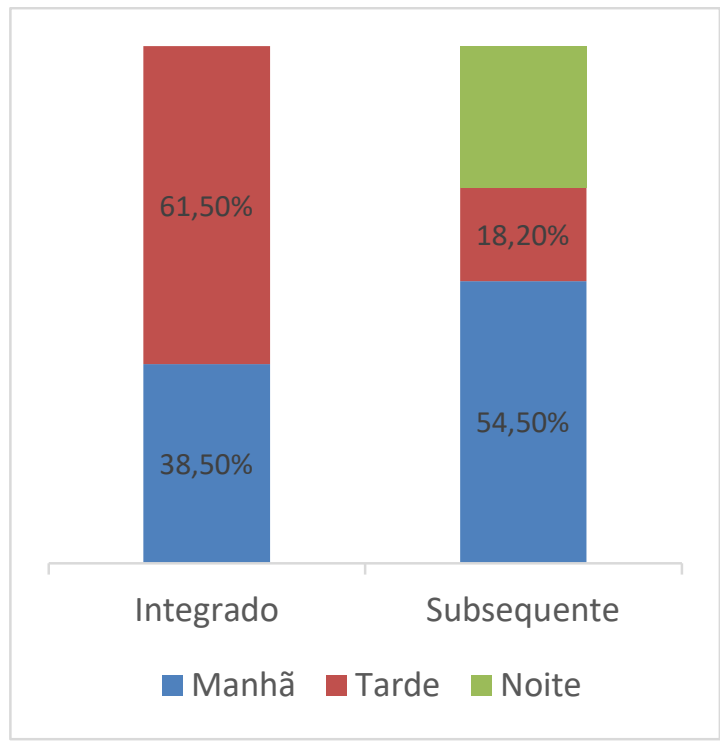

Fonte: Própria (2020)
Gráfico 2 (b): Distribuição de alunos por modalidade nos dois turnos da amostragem auxiliar

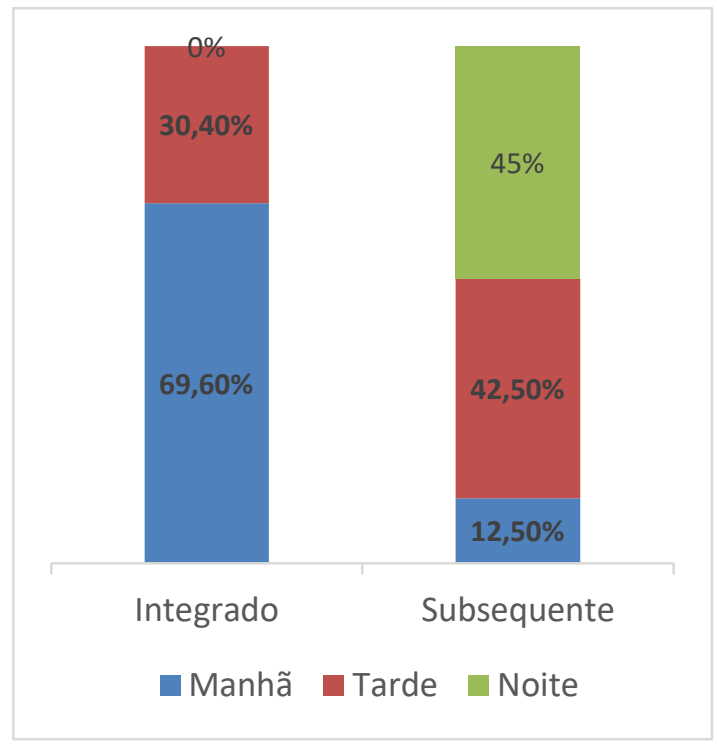

Fonte: Própria (2020)

Seguindo o perfil da amostragem dentro do IFPE, 35,1\% dos estudantes afirmam ser cotistas, ou seja, participaram do processo de cotas ao entrarem no IFPE; destes, 61,5\% cursam a modalidade Integrado. A análise do perfil do estudante também incluiu uma pergunta acerca da sua motivação ao fazer e escolher seu curso. Entre os estudantes de Saneamento da modalidade Integrado, como especifica a Tabela 1, a maioria $(49,9 \%)$ tinha como motivação "Apenas concluir o ensino médio"; já entre os estudantes da modalidade Subsequente, a maioria $(63,6 \%)$ dos estudantes escolheram a opção "Era o curso mais próximo do curso que quero fazer".

Tabela 1: Motivação dos estudantes de Saneamento para fazerem e escolherem seu curso

\begin{tabular}{|c|c|c|}
\hline & Integrado & Subsequente \\
\hline Era o curso mais próximo do curso que quero fazer & $30,8 \%$ & $63,6 \%$ \\
\hline Apenas concluir o ensino médio & $49,9 \%$ & $\mathrm{~N} / \mathrm{A}^{16}$ \\
\hline Vocação & $7,8 \%$ & $18,2 \%$ \\
\hline Estímulo familiar & $11,5 \%$ & $0 \%$ \\
\hline Estímulo de amigos & $0 \%$ & $18,2 \%$ \\
\hline Ensino de qualidade & $0 \%$ & $0 \%$ \\
\hline
\end{tabular}


Ao compararmos a mesma pergunta entre a amostra principal e a amostra auxiliar (como mostra a Tabela 2), nota-se um aumento de 24,4\% nas respostas "Vocação" entre os estudantes da modalidade Subsequente, indicando a motivação para fazer o curso de Saneamento predominantemente ligada à área geral de interesse do que no curso de Saneamento especificamente. É também interessante notar a diferença das respostas dos estudantes da modalidade Integrado entre a amostra principal e auxiliar: como é possível observar na Tabela 2, a amostragem auxiliar apresentou significantes menores índices na resposta "Apenas concluir o ensino médio" do que na amostragem principal.

Tabela 2: Motivação dos estudantes dos cursos técnicos e superiores do IFPE - campus Recife para fazerem e escolherem seu curso

\begin{tabular}{l|cc} 
& Integrado & Subsequente \\
\hline Era o curso mais próximo do curso que quero fazer & $46,7 \%$ & $45,2 \%$ \\
Apenas concluir o ensino médio & $19 \%$ & $\mathrm{~N}^{\mathrm{A}}{ }^{1}$ \\
Vocação & $19 \%$ & $42,6 \%$ \\
Estímulo familiar & $9,8 \%$ & $7,5 \%$ \\
Estímulo de amigos & $1,6 \%$ & $4,7 \%$ \\
Ensino de qualidade & $3,7 \%$ & $0 \%$
\end{tabular}

Fonte: Própria (2020)

Dessa forma, é importante observar que os estudantes de Saneamento da modalidade Integrado, tanto em relação aos da modalidade Subsequente do mesmo curso como aos da modalidade Integrado dos principais cursos do IFPE, possuem menores índices de resposta ligadas a vocação e aptidão ao seu curso em específico. Estes baixos índices podem ter diversas causas que não cabem à presente pesquisa investigá-los; mesmo assim, é importante lembrar que como sugere Much et al (2018), o efeito pedagógico desejado com o protagonismo estudantil requer esforço e interesse pessoal também dos alunos; dessa forma, a análise dos dados que serão apresentados adiante também deve levar em conta os baixos índices observados na motivação dos alunos com seus cursos em específico 


\section{Participação em atividades que incentivam o Protagonismo Estudantil}

A maioria das atividades extracurriculares incentivam maior participação ativa do estudante, algo indispensável em metodologias e atividades que promovam o protagonismo estudantil. O IFPE - campus Recife se destaca na quantidade e variedade de atividades extracurriculares oferecidas, sendo consideradas as estratégias de maior impacto para o incentivo do protagonismo estudantil no campus. O questionário aplicado com os discentes do Saneamento comtemplou esta questão, analisando a participação dos discentes nas principais atividades extracurriculares do campus. A primeira pergunta relacionada à participação neste tipo de atividades questiona: "Você gosta de desenvolver novos projetos?"; os estudantes de Saneamento apresentaram grande maioria, $86,5 \%$ das respostas, com a opção "Sim" marcada, como mostra o Gráfico 3.

Gráfico 3: Aptidão para desenvolver novos projetos entre os estudantes de Saneamento.

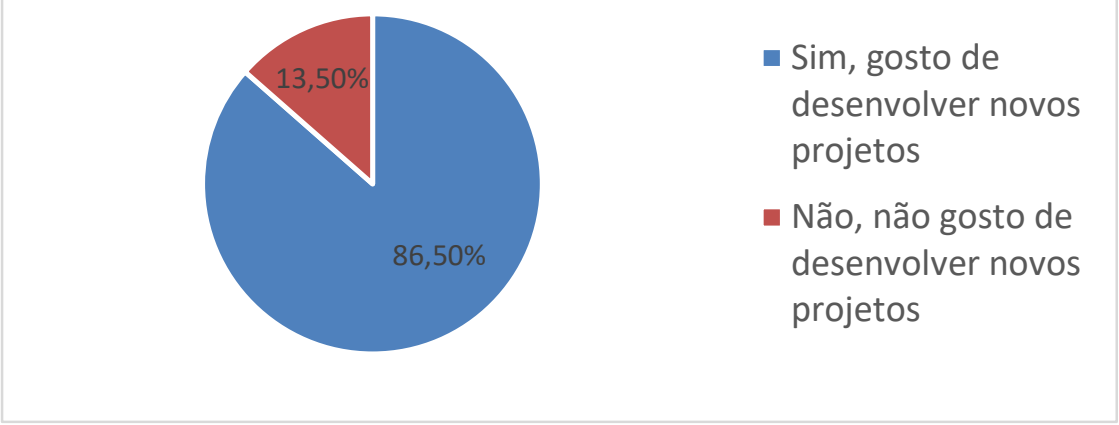

Fonte: Própria (2020)

As seguintes perguntas foram feitas com opções polares e mediram a participação do estudante nas seguintes atividades: movimentos estudantis (grêmio, diretório, acadêmico, entre outros), monitorias, projetos de pesquisa (iniciações científicas), projetos de extensão, voluntariado (centros comunitários, igrejas, associações, entre outros) e competições acadêmicas (olimpíadas, hackathons, competições de ideias, entre outros). Como o Gráfico 4 destaca, entre os estudantes de Saneamento, o número de respostas que selecionaram a opção "Não" foi significantemente menor do que o número de respostas que selecionaram a opção “Sim”, ou seja, a participação nestas atividades apresentou índices baixos, passando de 20\% apenas em duas atividades. 
Gráfico 4: Participação em atividades que estimulam o protagonismo estudantil entre as amostragens principal e auxiliar

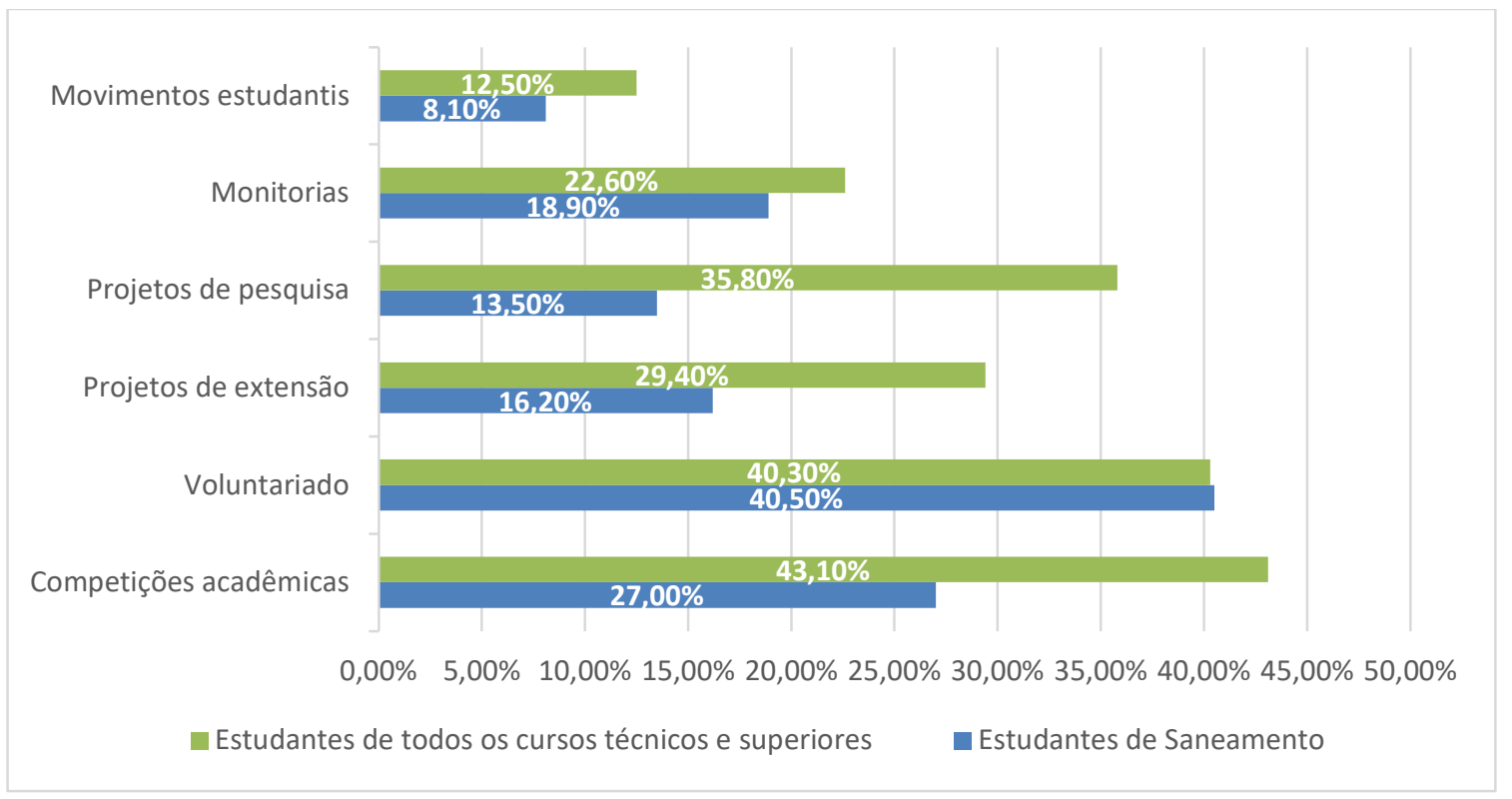

Fonte: Própria (2020)

A única atividade que apresentou maior participação entre os estudantes de Saneamento em relação à amostragem auxiliar foi a de voluntariado (40,5\%), tendo uma irrisória diferença de 0,2\%; esta, por sua vez, foi seguida de competições acadêmicas (27\%) e monitorias (18,9\%). Como o Gráfico 4 também mostra, ao compararmos os índices de participação nas atividades entre os estudantes de Saneamento e os estudantes dos principais cursos do IFPE campus Recife, notamos a grande diferença de participação do curso de Saneamento, principalmente nos índices de participação em projetos de extensão e projetos de pesquisa, números que representam aproximadamente metade dos observados nos outros cursos. Estes dados são especialmente alarmantes no âmbito da pesquisa e extensão, pois como descrito no Projeto Político Pedagógico Institucional (IFPE, 2012), a indissociabilidade entre ensino, pesquisa e extensão é um dos princípios pedagógicos do IFPE e o "PPP [Projeto Político Pedagógico] é a expressão da identidade institucional" (IFPE, 2012, p. 8); como então garantir que essa identidade esteja presente em toda a instituição, e especialmente nos cursos de Saneamento? Além disso, percebe-se incongruência entre os altos índices de aptidão dos estudantes em desenvolver novos projetos (como apresentado anteriormente no Gráfico 3) e as baixas taxas de participação nas atividades aqui apresentadas.

Durante a tabulação dos dados também se notou que 37,5\% dos estudantes do curso de Saneamento alegaram não participarem ou nunca terem participado em nenhuma das atividades descritas, como o Gráfico 5 sugere. 
Gráfico 5: Número de participação em diferentes atividades entre os estudantes de Saneamento

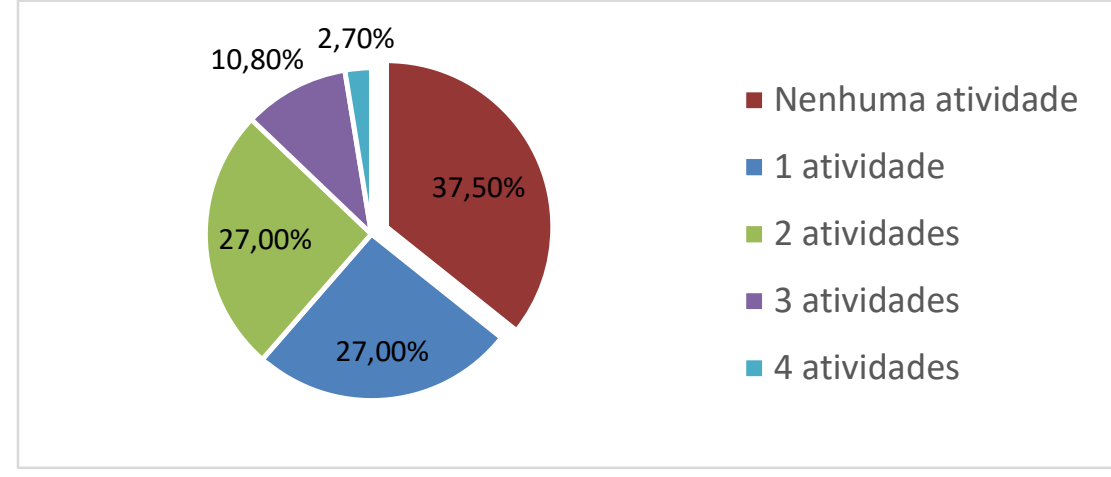

Fonte: Própria (2020)

Além dos dados de efetiva participação nas atividades descritas, também foi coletada a opinião dos estudantes acerca de quais atividades ou experiências eles acreditam poder mais beneficiar (direta ou indiretamente) o seu desenvolvimento pessoal, acadêmico e/ou profissional; dessa forma, além de analisar opinião sobre as atividades extracurriculares como as descritas anteriormente, essa nova pergunta também incluiu a opção "Conceitos e teoria bem explicados em sala de aula, monitoria em ensino, trabalhos de casa propostos em sala de aula, discussões em grupo em sala de aula, jogos pedagógicos em sala de aula, visitas técnicas", visando identificar também qual a aptidão e importância dada aos modelos e metodologias comuns e tradicionais dentro do IFPE - campus Recife quando comparado às principais atividades extracurriculares do campus. Como demonstra o Gráfico 6, mais da metade $(51,4 \%)$ dos estudantes de Saneamento consideraram a opção relacionada ao modelo comum de ensino como sendo a atividade mais impactante no seu futuro acadêmico e pessoal.

Gráfico 6 (a): Atividades consideradas importantes na amostragem principal

$$
\begin{aligned}
& \text { - Conceitos e } \\
& \text { teoria bem } \\
& \text { explicados... } \\
& \text { - Congressos } \\
& \text { Científicos, } \\
& \text { PIBIC... } \\
& \text { - Empresas } \\
& \text { júniores, } \\
& \text { hackatons... } \\
& \text { - Projetos de } \\
& \text { extensão... } \\
& \\
& \text { - Nenhuma das } \\
& \text { alternativas } \\
& \text { anteriores }
\end{aligned}
$$

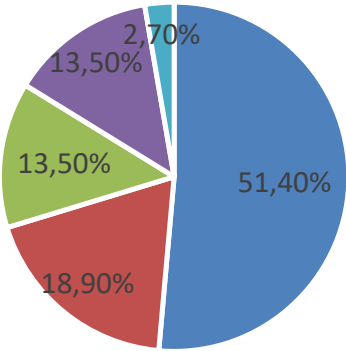

Gráfico 6 (b): Atividades consideradas importantes na amostragem auxiliar

- Conceitos e teoria bem explicados..

- Congressos Científicos, PIBIC ...

- Empresas Juniores, hackatons...

- Projetos de extensão ...

- Nenhuma das alternativas anteriores 
Ao compararmos as respostas dos estudantes de Saneamento junto dos da amostragem auxiliar, percebemos uma redução de respostas associadas ao modelo comum de ensino, indicando maior afinidade e acreditação à outras atividades como projetos de pesquisa e extensão, empresas júniores e hackathons entre os estudantes dos principais cursos do campus. Além disso, como o Gráfico 7 destaca, relacionando as respostas desta pergunta junto com a pergunta anteriormente apresentada "Você gosta de desenvolver novos projetos", nota-se que entre os estudantes de Saneamento que não gostam de desenvolver novos projetos, os percentuais de respostas relacionadas ao modelo comum de ensino aumentam substancialmente de $50 \%$ para $60 \%$ se comparadas aos estudantes que gostam de desenvolver novos projetos.

Gráfico 7 (a): Atividades consideradas importantes entre os estudantes de Saneamento que gostam de desenvolver novos projetos

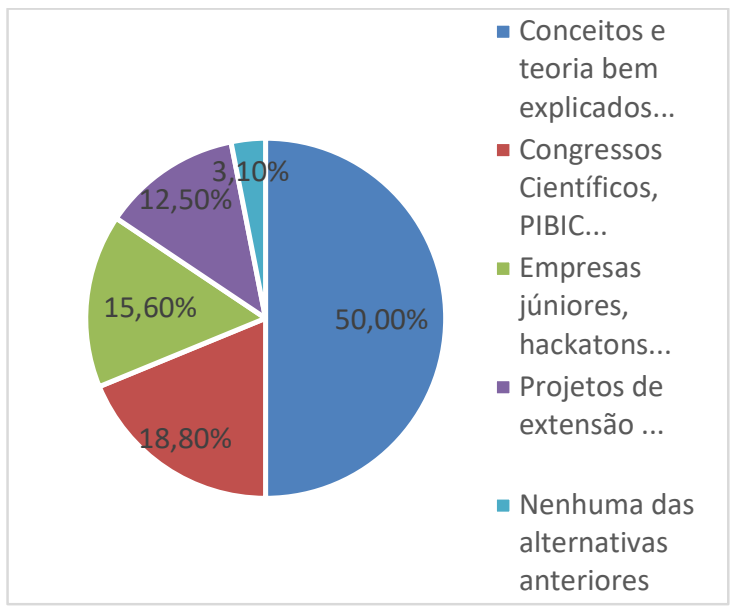

Fonte: Própria (2020)
Gráfico 7 (b): Atividades consideradas importantes entre os estudantes de Saneamento que não gostam de desenvolver novos projetos

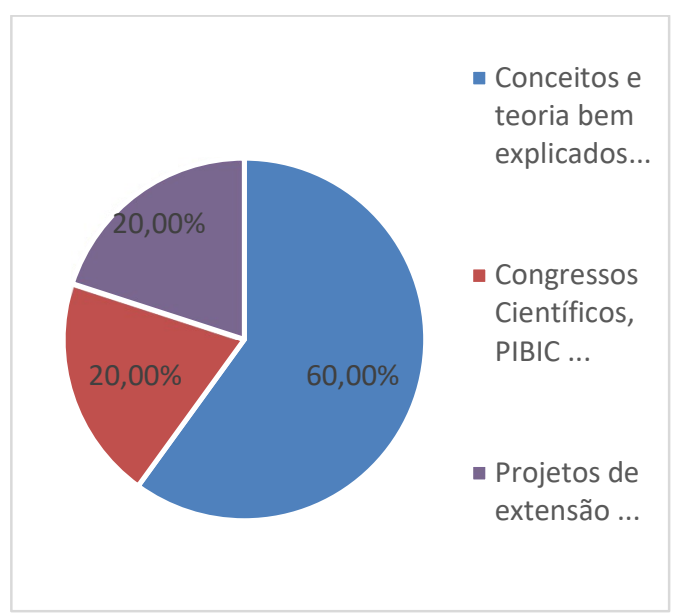

Fonte: Própria (2020)

\section{Percepção ao estímulo a atividades que incentivem o protagonismo estudantil}

Como analisado no tópico anterior, a participação e engajamento dos estudantes nas atividades é fundamental para o pleno desenvolvimento de características protagonistas. Embora a plena ciência dos conceitos relacionados ao protagonismo estudantil não seja obrigatória para a realização de atividades que envolvam o protagonismo estudantil ou para que o estudante seja protagonista de seu desenvolvimento, o conhecimento do protagonismo estudantil e de seus potenciais benefícios pode facilitar a busca do estudante ao mesmo. Durante o questionário, $64,9 \%$ 
dos estudantes responderam não saber o que é protagonismo estudantil, enquanto apenas $35,1 \%$ destes disseram conhecer o conceito.

Também deve-se considerar que o guia de todo o processo de uma estratégia pedagógica voltada ao protagonismo estudantil deve ser sempre um educador, que saiba todos os objetivos e metas que pretendem ser alcançados, além de como pretende alcançá-los, como raciocina Costa (2003):

Por se tratar de pessoas em condição peculiar do desenvolvimento, o protagonismo, mais do que justificar, pressupõe e exige a presença do educador como pólo ordenador (irradiador de referências) da relação do adolescente consigo mesmo, com os outros adolescentes e com a situação sobre a qual ele está atuando (COSTA, 2000, p. 3).

Dessa forma, dentro de um contexto escolar, torna-se também essencial a presença e iniciativa tanto da Instituição (num âmbito organizacional) como dos docentes e educadores da mesma em promover os potenciais benefícios do protagonismo e incentivar atividades que promovam o protagonismo estudantil. Dessa forma, investigou-se a percepção dos estudantes de Saneamento quanto ao incentivo e estímulo recebido para participação destas atividades no IFPE - campus Recife.

\subsection{Atividades extracurriculares}

Usando alternativas no modelo Likert, mediu-se a opinião dos estudantes sobre a frase "O IFPE estimula o protagonismo estudantil". Como o Gráfico 8 demonstra, a maioria dos estudantes concordam com a afirmação, tendo $54,1 \%$ das respostas sendo apenas "Concordo" e 32,4\% das respostas como "Concordo totalmente".

Gráfico 8: Opinião dos estudantes de Saneamento e dos cursos técnicos e superiores do IFPE campus Recife quanto ao estímulo do protagonismo estudantil

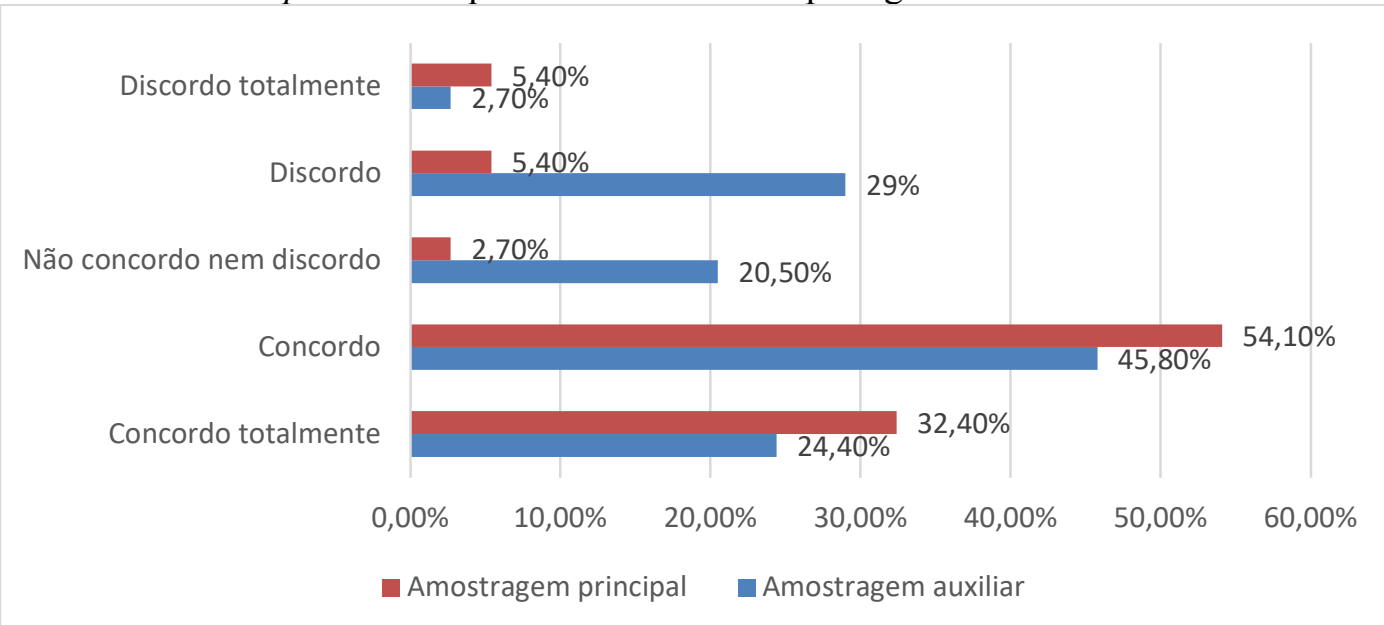

Fonte: Própria (2020) 
Apesar da relativa baixa participação nas atividades que incentivam o protagonismo estudantil - como discutido no tópico anterior - a maioria dos estudantes de Saneamento definem o IFPE como instituição estimuladora do protagonismo estudantil.

Analisando especificamente o estímulo recebido pelos professores, pediu-se que os estudantes do curso de Saneamento descrevessem com que frequência são recomendados pelos seus professores a participar em atividades ou experiências que estimulam o protagonismo estudantil. Conforme ilustra o Gráfico 9 (a), a resposta "Algumas vezes" representou maior índice entre os estudantes de Saneamento, seguida de "Muitas vezes" e "Poucas vezes".

Gráfico 9 (a): Frequência em que os professores recomendam a participação

em atividades que estimulam o protagonismo estudantil, segundo os estudantes do curso de Saneamento

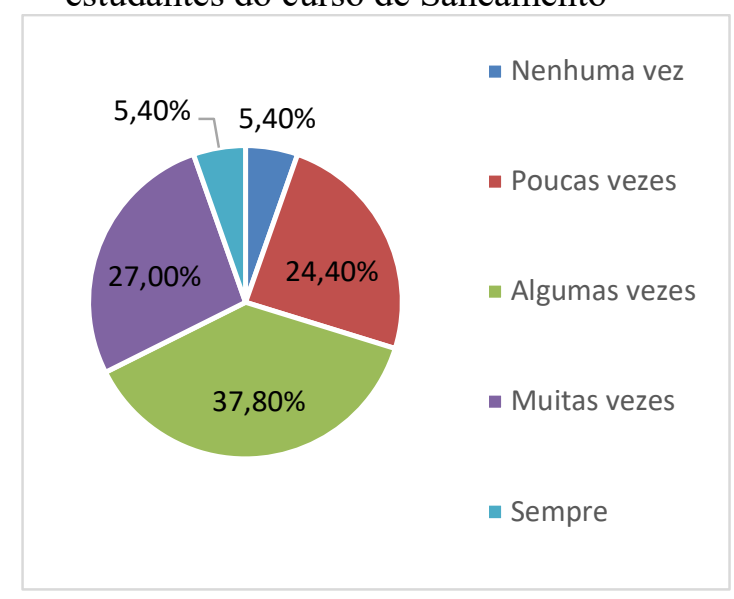

Fonte: Própria (2020)
Gráfico 9 (b): Frequência em que os professores recomendam a participação em atividades que estimulam o protagonismo estudantil, segundo os estudantes do curso de Saneamento do turno da manhã

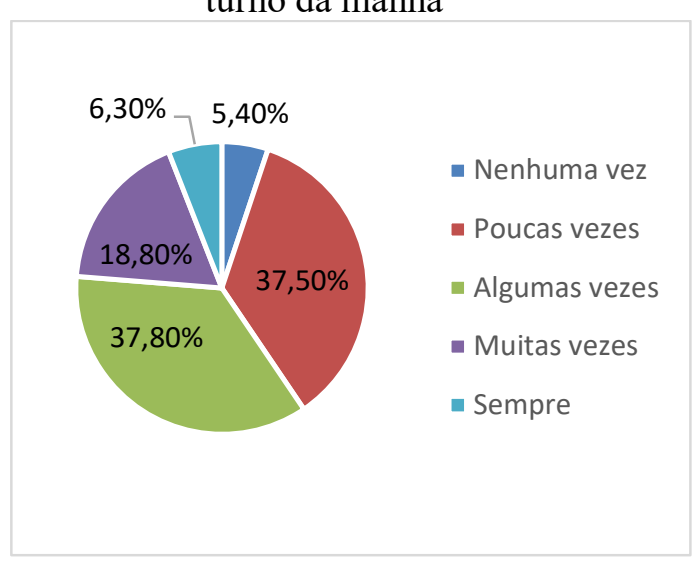

Fonte: Própria (2020)

Ao analisar as mesmas respostas, porém apenas entre os estudantes do turno da manhã (Gráfico 9b), notou-se ainda maior percentual de respostas "Poucas vezes", indicando menor estímulo recebido pelos estudantes da manhã em relação ao total. Estes dados, junto aos relativos à participação nas atividades, podem indicar que, embora o IFPE - campus Recife seja visto pelos estudantes de Saneamento como Instituição estimuladora do protagonismo estudantil, carece maior incentivo da parte dos professores, servidores mais presentes no dia-a-dia dos discentes, para a efetiva concretização do protagonismo estudantil no campus. Além disso, como citado anteriormente, o protagonismo estudantil requer, pela sua própria natureza, não só 
comprometimento docente, mas também comprometimento, esforço e vontade discente, podendo também indicar baixa iniciativa pessoal entre os estudantes de Saneamento.

\subsection{Disciplina de Empreendedorismo}

Dentre a base curricular dos cursos de Saneamento, a disciplina de Empreendedorismo pode ser considerada a mais estimuladora a resolução de problemas reais a partir dos conhecimentos técnicos adquiridos na sala de aula. Dessa forma, a participação e percepção dos estudantes nesta disciplina também foi analisada em específico.

Primeiramente, os estudantes foram indagados quanto à presença da disciplina de Empreendedorismo nos seus cursos; de fato, de acordo com os Projetos Pedagógicos (IFPE, 2013a; IFPE, 2013b) do curso, a disciplina está presente tanto na modalidade Integrado quanto na modalidade Subsequente dos cursos de Saneamento, mesmo assim, 43,2\% alegaram não saber da presença da disciplina, 19,8\% disseram que a disciplina não existia no seu curso e apenas $37,8 \%$ dos estudantes de Saneamento responderam que sabiam da presença da disciplina em seu curso. Dos que alegaram ter ciência da disciplina, apenas $2,7 \%$ (em relação ao total) ainda não tinham a cursado, como demonstra o Gráfico 10.

Gráfico 10: Ciência e participação na disciplina de Empreendedorismo entre os estudantes de Saneamento

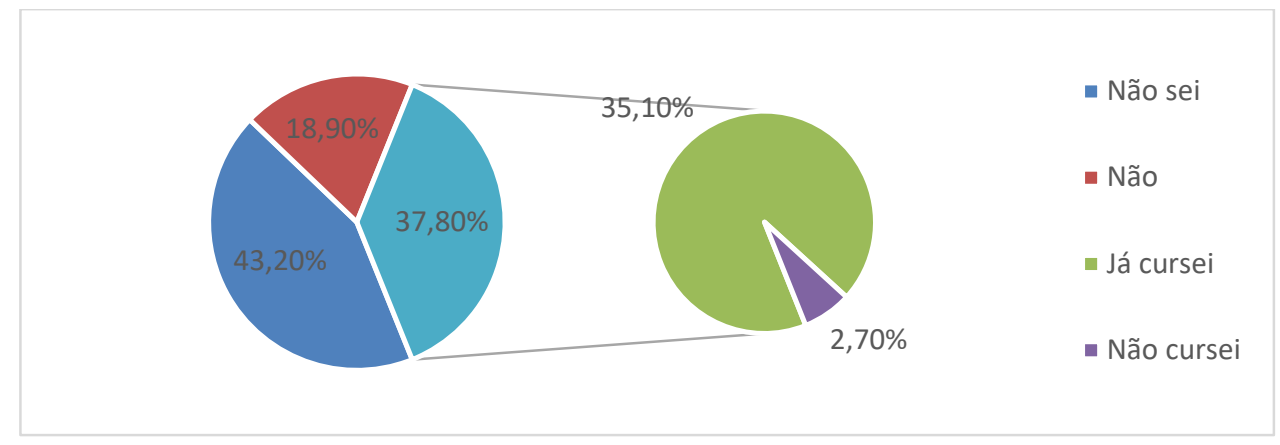

Fonte: Própria (2020)

Quanto à experiência dos estudantes que cursaram a disciplina, 46,2\% destes assinalaram a alternativa "Positiva, pois os conteúdos tinham relação com o mundo real e me ajudaram a pensar em empreender", enquanto $23,1 \%$ escolheram a opção "A disciplina foi boa, o professor tinha conhecimento, mas não tinha relação com meu objetivo de vida" e 15,4\% alegaram que "Foi uma disciplina que se tivesse sido ofertada no início do curso poderia ter ajudado muito a compreender como fazer o conhecimento 
técnico se transformar em uma oportunidade de negócio". De fato, a preocupação anterior é válida: de acordo com os Projetos Pedagógicos (IFPE, 2013a; IFPE, 2013b) dos cursos de Saneamento (Integrado e Subsequente), a disciplina de Empreendedorismo é ministrada apenas nos últimos períodos dos cursos, sendo no último ( $4^{\circ}$ período) da modalidade Subsequente e no $7^{\circ}$ período da modalidade Integrado. Isto, somado ao baixo conhecimento da disciplina entre os discentes que ainda não a cursaram, pode indicar pouca relevância do tema ou da disciplina entre os estudantes de Saneamento.

\section{CONCLUSÕES}

O Projeto Pedagógico do curso de Saneamento do IFPE - campus Recife destaca entre seus objetivos a formação de profissionais não apenas com conhecimentos técnicos e teóricos, mas com competências comportamentais, interpessoais e éticas. $\mathrm{O}$ protagonismo estudantil vem como alternativa aos modelos tradicionais de ensino, quebrando as barreiras comuns entre os estudantes e adultos, tornando-os agentes de seu próprio aprendizado.

As principais atividades extracurriculares do campus que estimulam o protagonismo estudantil foram mapeadas e utilizadas para medir e analisar a participação dos estudantes do curso de Saneamento. Os índices de participação nestas atividades apresentaram-se baixos, passando de $20 \%$ em apenas 2 das atividades listadas; além disso, também se mantiveram, na maioria dos casos, inferiores em relação aos da amostragem auxiliar. É importante ressaltar os baixos índices de atividades de pesquisa e extensão, atividades que, junto com o ensino, constituem um dos principais eixos pedagógicos do IFPE. Estes baixos índices de participação e o fato de 37,5\% dos estudantes não participarem em nenhuma atividade extracurricular contrastam com a grande maioria dos estudantes de Saneamento afirmarem gostar de desenvolver novos projetos.

Os dados relativos à participação também convergem para o fato de a maioria dos estudantes de Saneamento $(51,4 \%)$ considerarem o modelo tradicional de ensino o mais importante para seu desenvolvimento acadêmico e pessoal.

A análise do estímulo percebido pelos estudantes de Saneamento à participação nas atividades mapeadas apontou que mesmo com os baixos índices de participação nas atividades, o IFPE, enquanto Instituição, é visto como estimulador do protagonismo 
estudantil. Mesmo assim, as respostas com relação ao estímulo recebido dos professores indicaram que carece de maior incentivo destes, os servidores mais presentes no dia-adia dos discentes. Ademais, a análise da disciplina de "Empreendedorismo", considerada a mais estimuladora do protagonismo estudantil, pode indicar baixa relevância do tema ou da disciplina entre os estudantes de Saneamento.

Pela quantidade de atividades extracurriculares promovidas pelo IFPE - campus Recife, já é possível notar a grande mobilização de esforços desenvolvidos pelo Instituto e que podem culminar numa maior promoção do protagonismo estudantil. Mesmo assim, o questionário aplicado aos discentes demonstra que esta não é a situação necessariamente geral dentro do campus. É possível concluir que a participação, estímulo e interesse dos estudantes de Saneamento em atividades que promovem o protagonismo estudantil é, em geral, baixa, principalmente se relacionarmos com os dados dos outros cursos. Dessa forma, ainda existe potencial para maior desenvolvimento do tema protagonismo estudantil especialmente entre o curso de Saneamento.

Ainda existem muitas lacunas e oportunidades de pesquisa a respeito do protagonismo estudantil no IFPE - campus Recife. Os dados e análises produzidos na presente pesquisa contribuem para a geração de novos questionamentos e pesquisas na área, principalmente em relação às causas e consequências dos resultados aqui obtidos, levantando ainda mais questões a serem desenvolvidas futuramente.

\section{REFERÊNCIAS}

ABERASTURY, Arminda; KNOBEL, Mauricio. Adolescência normal: um enfoque psicanalítico. Trad. de Suzana Maria Garagoray Ballve. Porto Alegre: Artes Médicas, 1981. 92p. Disponível em: http://www.academia.edu/download/44407073/Aberastury_A._Adolescencia_norma 1.pdf. Acesso em: 12 set. 2020.

COSTA, Antônio Carlos Gomes da. Protagonismo juvenil: adolescência, educação e participação democrática. Salvador: Fundação Odebrecht, 2000.

FERRETTI, Celso; ZIBAS, Dagmar; TARTUCE, Gisela Lobo. Protagonismo juvenil na literatura especializada e na reforma do ensino médio. Cadernos de pesquisa, $v$. 34, n. 122, p. 411-423, 2004. Disponível https://www.scielo.br/scielo.php?pid=S0100-

$15742004000200007 \&$ script=sci_arttext\&tlng=pt. Acesso em: 8 ago. 2020.

FILION, Louis Jacques. Empreendedorismo e gerenciamento: processos distintos, 
porém complementares. RAE-Revista de Administração de Empresas, p. 2-7, 2000.

Disponível

em:

https://bibliotecadigital.fgv.br/ojs/index.php/rae/article/viewFile/37736/36485. Acesso em: 1 set. 2020.

FLEURY, Maria Tereza Leme; WERLANG, Sergio Ribeiro da Costa. Pesquisa aplicada: conceitos e abordagens. Anuário de Pesquisa GVPesquisa, São Paulo, nov. 2017.

Disponível

em:

http://bibliotecadigital.fgv.br/ojs/index.php/apgvpesquisa/article/view/72796. Acesso em: 30 jul. 2020.

Instituto Federal de Pernambuco. Departamento Acadêmico de Infraestrutura e Construção Civil. Projeto Pedagógico: Curso Técnico em Saneamento Integrado, 2013a.

Disponível

em: https://www.ifpe.edu.br/campus/recife/cursos/tecnicos/integrados/saneamento/projetopedagogico/ppc_saneamento_integrado.pdf. Acesso em: 15 set. 2020.

Instituto Federal de Pernambuco. Departamento Acadêmico de Infraestrutura e Construção Civil. Projeto Pedagógico: Curso Técnico em Saneamento Subsequente, $2013 b$.

Disponível

em:

https://www.ifpe.edu.br/campus/recife/cursos/tecnicos/subsequente/saneamento/projetopedagogico/ppc-saneamento-subsequente-final-27-12-2013.pdf. Acesso em: 15 set. 2020.

Instituto Federal de Pernambuco. Planilha quantitativa de alunos matriculados disponibilizada pela gestão. Recife, 2020.

Instituto Federal de Pernambuco. Projeto Político Pedagógico Institucional. Recife, 2012. Disponível em: https://www.ifpe.edu.br/o-ifpe/ensino/documentosnorteadores/projeto-politico-pedagogico-institucional-pppi-_2009-2013.pdf. Acesso em: 20 set. 2020.

LAKATOS, Eva Maria; MARCONI, Marina de Andrade. Fundamentos de metodologia científica. 5 ed. São Paulo: Atlas, 2003.

MUCH, Liane et al. Mudança na prática docente: incentivando o protagonismo discente. RELACult - Revista Latino-Americana de Estudos em Cultura e Sociedade, v. 4, 2018.2 Disponível em: https://www.claec.org/periodicos/index.php/relacult/article/view/805. Acesso em: 13 ago. 2020.

SILVA, Thais Gama da. Protagonismo na adolescência: A escola como espaço e lugar de desenvolvimento humano. Curitiba: 2009. 142p. Dissertação (Mestre em Educação). Universidade Federal do Paraná. Disponível em: http://www.ppge.ufpr.br/teses/teses/M09_gamasilva.pdf. Acesso em: 20 ago. 2020.

STOCKMANNS, Jussara Isabel. Pedagogia Empreendedora. Paraná: Editora Unicentro, 2014. Disponível em: http://repositorio.unicentro.br:8080/jspui/handle/123456789/840. 